\title{
Ajustar la representación a las consecuencias del progreso. La reforma constitucional argentina de 1898 y los dilemas de un federalismo
}

\author{
por \\ Lisandro Gallucci ${ }^{1}$ \\ CONICET — Universidad Nacional de San Martín
}

\begin{abstract}
Este artículo ofrece un análisis de la reforma de la Constitución argentina practicada en 1898, mayormente desatendida por la historiografía sobre el periodo. En particular, el estudio apunta a explorar las razones por las cuales la convención reformadora introdujo ciertos cambios en el sistema representativo federal, al mismo tiempo que descartó otros. Se intenta así contribuir a una imagen más compleja de la política argentina entre 1880 y 1916.
\end{abstract}

Palabras Clave: Historia política; Argentina; Constitución; Federalismo.

Cómo CITAR ESTE artículo / Citation: Gallucci, Lisandro, “Ajustar la representación a las consecuencias del progreso. La reforma constitucional argentina de 1898 y los dilemas de un federalismo", Revista de Indias, LXXX/279 (Madrid, 2020): 447-479. https://doi.org/10.3989/ revindias.2020.013.

En septiembre de 1869 , a poco de cumplirse el primer año de la presidencia de Domingo F. Sarmiento, la República Argentina llevó adelante su primer censo nacional. Aprobados por el Congreso de la Nación en 1872, los resultados fueron publicados ese mismo año, siendo estimada la población argentina en torno a un millón ochocientos mil individuos. Para quienes lo habían llevado adelante, los datos obtenidos revelaban ante todo la variedad y la magnitud de los obstáculos que la joven nación debía todavía superar para alcanzar un futuro que, pese a todo, no dejaba de ser imaginado como plenamente venturoso. Aún considerados incipientes, los progresos realizados permitían a los respon-

\footnotetext{
1 lisandrogallucci@gmail.com, ORCID iD: https://orcid.org/0000-0003-1406-2571
} 
sables del censo entrever la emergencia de nuevos desafíos. Frente a la doble evidencia de que el crecimiento demográfico del país obedecía en buena parte a la inmigración ultramarina y que esta tendía a concentrarse en ciertas regiones del país, se preguntaban si la representación en la Cámara de Diputados de la Nación debía seguir ajustándose a proporciones demográficas — como lo dictaba la Constitución desde 1853- y si, en todo caso, se debía tomar por base a la población absoluta o considerar en cambio solo a la argentina. «Cuestiones son estas de mucha trascendencia», advertían al conjeturar la futura evolución del país, «y que han de surjir en vista de la enorme población estranjera con que algunos estados empiezan a pesar en el seno de la unión» ${ }^{2}$. Pocos días después de aprobar los resultados del censo, el Congreso sancionó una ley por la que ajustó el número de diputados de cada una de las catorce provincias ${ }^{3}$.

Los desafíos señalados en 1872 se confirmaron ampliamente en el segundo censo nacional, recién efectuado en 1895. Al cabo de ese cuarto de siglo, la Argentina había superado los cuatro millones de habitantes, la proporción de extranjeros se había elevado hasta alcanzar una cuarta parte de la población -en 1869 representaban el $12 \%$ - y, no menos importante, la desigual distribución de ese crecimiento entre las provincias se había vuelto aún más pronunciada. Pero si en 1872 la oficialización de los resultados del primer censo dio lugar a una inmediata actualización del número de diputados asignados a cada provincia, la aprobación, en 1897, de los datos obtenidos del censo realizado dos años antes, no condujo a una repetición de aquel procedimiento sino a la reforma de la Constitución, la primera luego de más de tres décadas desde su última modificación. El presente artículo se ocupa de analizar la reforma constitucional de 1898, con el propósito de observar de qué modo los actores políticos respondieron a los desafíos que el sistema representativo federal enfrentaba como resultado de las profundas y aceleradas transformaciones experimentadas por el país en dicho periodo ${ }^{4}$.

2 Primer Censo de la República Argentina. 1869, Buenos Aires, Imprenta del Porvenir, 1872, XXVII.

${ }^{3}$ La ley se limitó a aplicar la proporción establecida en la Constitución de 1853, que asignaba un diputado nacional por cada 20.000 habitantes o fracción no menor a 10.000 . En consecuencia, la provincia de Buenos Aires pasó de contar con 12 diputados a tener 25, mientras que Córdoba pasó de 6 a 11, Entre Ríos de 2 a 7 y Santiago del Estero de 4 a 7. Las demás provincias obtuvieron entre uno o dos diputados más, con la excepción de Mendoza, Jujuy y La Rioja, que mantuvieron la misma cantidad (3, 2 y 2, respectivamente). Así, la Cámara de Diputados pasó de 50 a 86 legisladores. Por supuesto, no hubo cambios en la Cámara de Senadores, en la que regía una representación territorial fija de dos senadores por cada distrito representado.

4 Para una mirada de conjunto sobre tales cambios, Sabato, 2012. 
No obstante la gravedad con que los protagonistas abordaron la reforma de 1898, esta no ha sido objeto de especial consideración historiográfica. En algunas de las obras más reconocidas sobre la política argentina hacia fines del siglo XIX apenas es posible hallar alguna referencia a dicha convención ${ }^{5}$, y lo mismo ocurre con producciones más recientes en la materia ${ }^{6}$. Acaso esto obedezca a la menor relevancia otorgada a la reforma de 1898, en contraste con otros episodios de la historia constitucional del país, como la sanción, en 1853, de la Constitución que dio nacimiento a la Confederación Argentina; las reformas de 1860 y 1866, que afianzaron la construcción del Estado nacional poniendo fin a la secesión de la provincia de Buenos Aires y asegurando la propiedad federal de los recursos aduaneros; o la que el peronismo concretó en 1949, como pieza clave en su edificación de un nuevo régimen político. A ello quizá se deba que la de 1898 haya sido descrita como «una muy limitada reforma de la Constitución nacional que amplió de 5 a 8 el número de ministerios» ${ }^{7}$, olvidando la modificación que mayor importancia tuvo para los convencionales, como fue el cambio de la base demográfica para la asignación de diputados nacionales a cada uno de los distritos representados en el Congreso, que quedó fijada en un legislador por cada 33.000 habitantes o fracción no inferior a 16.500 . Ni aún el hecho de que esta última regla se mantenga en el texto constitucional vigente - aunque más como un vestigio de tensiones no resueltas en el federalismo argentino que como una norma efectiva - ha bastado para incitar una mirada más atenta hacia dicha reforma ${ }^{8}$.

Pero en lo que se podría señalar un motivo del escaso interés historiográfico en la reforma de 1898, esto es, el reducido espectro de cambios que introdujo en la Constitución, es también posible identificar un indicio de lo que dicha reforma tiene de relevante desde un enfoque histórico. En efecto, el hecho de que fuera desde su inicio limitada a una serie mínima de modificaciones revela el cuidado con que los legisladores que la pusieron en marcha creían necesario proceder al intervenir sobre una Constitución a la que concebían como una pieza orgánica de un progreso argentino que buscaban preservar. Esta actitud hacia el texto constitucional, que podría calificarse de conservadora, mal podría entenderse como expresión de un «liberalismo clá-

5 Botana, 1994. Botana y Gallo, 1997.

6 Alonso, 2010. Castro, 2012.

7 Gallo, 2013a: 56.

8 Pese a estar todavía consagrada en la Constitución, la proporcionalidad fijada en 1898 sufrió numerosas alteraciones que explican que dicha prescripción no sea la que determina el número de diputados asignados a cada una de las provincias. Sobre las modificaciones operadas en la materia durante el siglo XX, Reynoso, 2012. 
sico» epistemológicamente incapaz de advertir la emergencia de nuevos problemas - como la denominada cuestión social - o como gesto de un «régimen oligárquico» que, asediado por presiones democráticas, no habría tenido más alternativa que refugiarse en una creciente esclerosis institucional. Cualesquiera que hayan sido sus motivaciones, es bien conocido que importantes sectores de las dirigencias políticas de finales del siglo XIX fueron capaces de formular muy importantes innovaciones institucionales que iban desde el sufragio al derecho laboral, entre otros aspectos, y que la suerte adversa de algunas de esas propuestas no respondió simplemente a la oposición de un inveterado ethos excluyente atribuible a ciertos sectores sociales ${ }^{9}$.

El temple conservador que sin duda caracterizó a la reforma de 1898 hizo por ejemplo que, aun cuando algunas voces, incluidas las de algunos convencionales, alertaban sobre las amenazas contra la nación argentina que veían en la voluminosa población extranjera, la convención no se apartara de la mirada que reconocía en la inmigración europea uno de los factores principales del progreso argentino, y que por lo tanto no innovara frente a la gravitación de esa población en la base demográfica de representación parlamentaria, fenómeno ya advertido por los responsables del censo de 1869. La actitud conservadora de quienes participaron en la reforma de 1898, y en definitiva de amplios sectores de la clase política de la que formaban parte, no expresaba un rechazo doctrinario al liberalismo o a la idea de progreso, al modo de otros conservadorismos europeos o latinoamericanos. Se trataba, por el contrario, de una posición sobre todo interesada en la conservación de un entramado jurídico-institucional que había demostrado ser muy eficaz en favorecer los acelerados progresos alcanzados por la nación en su breve vida constitucional. Desde esta concepción del vínculo entre instituciones y sociedad, que era conservadora porque rechazaba la experimentación sobre esta última mediante cambios radicales en las primeras, las reformas a la Constitución debían ser muy limitadas y además efectuadas con toda la precisión necesaria para no afectar esa que consideraban una pieza constitutiva de la nación argentina. El mismo criterio era públicamente sostenido desde la prensa, como lo hacía La Nación al afirmar que las reformas constitucionales debían hacerse «con espíritu conservador, tocándose únicamente los puntos que sea indispensable modificar» ${ }^{10}$, y como también lo hacía Tribuna al insistir en que la convención debía limitarse a tratar los puntos señalados por la ley de reforma sancionada por el Congreso ${ }^{11}$.

9 Sobre la disposición reformista de la clase política argentina de finales del siglo XIX y comienzos del XX, Zimmermann, 1995 y De Privitellio, 2011, entre otros.

10 La Nación, 10/3/1898.

11 Tribuna, 22/1/1898. 
El propósito de este artículo no es el de advertir un descuido historiográfico al que habría que poner término, como si en dicho acontecimiento hubiera alguna especie de clave, hasta ahora no revelada, que iluminaría bajo una nueva luz la entera vida política del periodo. Más bien, el objetivo consiste en analizar la reforma de 1898 para aproximarse a los modos en que los actores políticos del periodo pensaron en torno a una serie de problemáticas relativas a la representación política que derivaban de las intensas y aceleradas transformaciones experimentadas por el país en el último cuarto del siglo XIX. En ese periodo, la República no solo vio duplicada su población sino también sus dominios soberanos, dando lugar a la aparición de nueve nuevas unidades, los Territorios Nacionales, que representaban casi la mitad de todo el territorio argentino y que estaban bajo dependencia del gobierno federal, como también ocurría con la ciudad de Buenos Aires desde su federalización en 1880. A esto se añadía la intensificación de los conflictos limítrofes que, como resultado de esa expansión y de las aspiraciones territoriales de Chile, llevaban a sectores de la opinión pública de ambos países a presionar a sus autoridades para lanzarse en guerra contra la nación vecina. El de 1898 era por lo tanto un país muy diferente de aquel que el censo de 1869 había mostrado. En este nuevo escenario, la convención reformadora buscó ajustar la representación parlamentaria a las profundas transformaciones, demográficas pero también territoriales, que acentuaban tensiones ya presentes en el federalismo argentino. Con este propósito, la primera sección de este artículo ofrece una descripción general de los desafíos identificados por los actores políticos de finales del siglo XIX como producto de aquellos cambios. En el segundo apartado se detallan las características de la iniciativa de reforma, mientras que en el tercero se exploran las concepciones desde las que los convencionales reflexionaron acerca de la representación política y los desafíos que esta hallaba en el federalismo argentino. La cuarta sección pone foco en una cuestión relevante en los debates suscitados durante la reforma, como fue la relativa al lugar que los Territorios debían ocupar en el sistema representativo federal. Por último, en las conclusiones se busca resaltar algunos de los elementos que invitan a revisar cierta imagen del orden político de finales del siglo XIX como sustentado en criterios centralistas y restrictivos que habrían subvertido un federalismo presuntamente más verdadero.

\section{ArgentinA, FIN DE SIGLO}

El orden político que funcionó en Argentina en la década de 1880 se caracterizó por su estabilidad, condición que, a juzgar por los estudios más recientes, 
fue menos el resultado de una virtual neutralización de la vida política a manos de un sector social bien preciso, que el producto de una compleja política de acuerdos que, como demostraría la década inmediatamente posterior, fueron menos sólidos y duraderos de lo que sugiere un cuadro canónico del periodo. Uno de los pilares de la legitimidad, por supuesto no libre de cuestionamientos, que ese orden logró construir, derivaba de haber superado el tipo de conflictos que habían marcado la política argentina desde la constitución misma de la República $^{12}$. Los alzamientos encabezados por caudillos, y en un sentido más general la apelación a las armas como expresión de virtud cívica ${ }^{13}$, fueron eficazmente mostrados como imágenes de un pasado ya desaparecido, al que una nueva época de progresos económicos y políticos hacía imposible volver ${ }^{14}$. El febril crecimiento que el país experimentó desde 1880 convenció a diversos actores de la irreversibilidad de los cambios producidos en la vida política y de que su persistencia como partes relevantes en el juego del poder dependería de la capacidad que tuvieran para adaptarse a los nuevos tiempos. De esa manera, el Partido Autonomista Nacional (PAN) logró consolidarse como un ámbito capaz de atraer a diversos sectores dirigentes para dirimir, siempre mediante acuerdos tejidos al interior del partido, la distribución del poder y de los recur$\operatorname{sos}^{15}$. Esta nueva dinámica aumentó la previsibilidad del juego político, en base a la estructuración de una densa trama de vínculos en la que tenían un peso no menor las relaciones personales cultivadas entre quienes integraban las distintas jerarquías de la clase política de esos años ${ }^{16}$. En ese orden, muchos actores vieron una de las condiciones esenciales que habían hecho posible el definitivo ingreso del país a una vía de progreso que prometía conducirlo hacia un destino de creciente prosperidad.

Pese a todo, ese orden político sufrió fuertes impugnaciones, que apuntaron a las prácticas en base a las que se edificó, pero no contra aquel horizonte de progreso sobre cuya deseabilidad no parecía haber mayores dudas. El más resonante de esos desafíos fue la revolución de julio de 1890, protagonizada por viejos y nuevos actores políticos que se consideraban marginados de la política de acuerdos imperante, a la que acusaban de haber provocado la extinción de la virtud cívica y la corrupción de la república ${ }^{17}$. Aun cuando

12 Sobre la política argentina entre las décadas de 1850 y 1870, Bragoni y Míguez, 2010 y Sabato, 2012.

13 Bonaudo y Sonzogni, 1999. Sabato, 2003; 2009.

14 Halperin Donghi, 1998.

15 Botana, 2012.

16 Alonso, 2000.

17 Rojkind, 2012. Reyes, 2016. 
esa política mostró capacidad para responder al desafío de 1890, logrando que las filas revolucionarias resultaran finalmente divididas por su diferente disposición al acuerdo ${ }^{18}$, parece de todas formas posible entender que el orden político vigente quedó desde entonces envuelto en una crisis de legitimidad que no solo daría aliento a la aventura revolucionaria del radicalismo en 1893, sino además a una profundización de las disputas internas al PAN que socavaron el predominio político construido mediante el partido ${ }^{19}$.

Pero además de esos acontecimientos de directa relación con las disputas por el poder, las representaciones de los actores acerca del orden político vigente también respondían a las intensas transformaciones económicas y sociales por las que transitaba el país ${ }^{20}$. En este sentido, la imagen que para muchos observadores cobraría validez como descripción del estado general de la república era la de una disociación entre, por un lado, una sociedad civil abierta y dinámica $\mathrm{y}$, por el otro, un régimen político cerrado y estático. Según esas miradas, las instituciones políticas del país fallaban en producir una representación fidedigna de la sociedad, a la que algunos se proponían llegar mediante una vía revolucionaria, pero a la que sectores más numerosos entendían posible arribar a través de un camino de reformas. Esta última postura no solo fue sostenida por quienes lanzaban sus críticas contra el orden político vigente, sino inclusive por muchos de sus más destacados protagonistas, como por ejemplo ocurrió en la segunda presidencia de Julio A. Roca (1898-1904), durante la cual se dio impulso a una serie de reformas que, al menos en ciertos aspectos, suponían una profunda revisión de las líneas directrices de su primer mandato (1880-1886) ${ }^{21}$. Extendida en amplios sectores políticos, tanto del gobierno como de la oposición, esa preocupación por adecuar las instituciones representativas a la nueva fisonomía que el país adquiría como producto de las intensas transformaciones sociales operadas en las dos últimas décadas del siglo, animó también la reforma constitucional de 1898.

Aun cuando no pasaban desapercibidos para nadie, esos cambios se verificaron de manera patente en 1895, cuando tuvo lugar el segundo censo nacional, empresa cuya misma magnitud daba cuenta del incremento de las

18 Alonso, 2000. Gallo, 2013b.

19 Castro, 2012.

20 Gallo, 1992.

21 La reforma electoral de 1902, que introdujo un sistema electoral de circunscripciones uninominales como medio para alcanzar la representación de los intereses gestados en el seno de una sociedad argentina más heterogénea y compleja, constituye un ejemplo de esa orientación reformista. Sobre la reforma de 1902, De Privitellio, 2006. Otra expresión del mismo impulso reformista fue la iniciativa del gobierno, finalmente frustrada, de establecer un Código de Trabajo. Zimmermann, 1995. 
capacidades burocráticas del Estado argentino 22 . Entre 1869 y 1895 , una población de 1.877.490 habitantes se había convertido en una de 4.044.911. Ese vertiginoso crecimiento demográfico, en gran medida nutrido por los flujos migratorios que hacia finales del siglo XIX hicieron de la Argentina uno de los destinos más importantes del mundo, tuvo profundas consecuencias sobre el país, no solo porque hizo posible la gran expansión económica que, aún con altibajos, caracterizó a esas décadas, sino también por los efectos que produjo sobre otros aspectos de esa sociedad.

En primer término, la creciente presencia de población extranjera, quintuplicada entre 1869 y 1895, despertó ansiedad entre aquellos que comenzaron a considerarla un factor amenazante para la nacionalidad argentina. Motivado por una u otra razón, el desinterés que esa población foránea mostraba en adoptar la ciudadanía argentina, manteniendo además las prácticas culturales de sus países de origen, dio aliento a la emergencia de discursos que sostenían ideas más abiertamente exclusivistas acerca de la nación, y también a crecientes presiones para que el Estado adoptara una actitud más activa en la promoción de la nacionalidad ${ }^{23}$. Estas aprensiones eran también alimentadas por la situación de los Territorios, cuya condición general de poco poblados y de limítrofes con los países vecinos, hacía que sus importantes proporciones de población extranjera resultaran especialmente inquietantes para algunos observadores, sobre todo cuando muchos de estos consideraban inminente el inicio de una guerra con Chile ${ }^{24}$. Concebidos como respuesta a tales desafíos, los programas de educación patriótica implementados en las escuelas públicas desde la última década del siglo XIX constituyeron una política que se demostró exitosa para alcanzar la nacionalización de las nuevas generaciones de argentinos, a lo que asimismo coadyuvó la instauración del servicio militar obligatorio para la población masculina, a partir de 1901.

Pero si el reto de esa voluminosa población extranjera fue de algún modo resuelto a través de tales medidas - aunque al cabo de algunas décadas y sin impedir que ese flujo migratorio transformara de manera profunda y definitiva la vida social y cultural argentina-, no ocurrió lo mismo con las tensiones

22 De acuerdo a Otero, 2006: 198, el censo de 1895 marcó una ruptura en la historia censal argentina, sobre todo por el volumen de recursos movilizados por el Estado para su realización. En efecto, dicho operativo implicó la movilización de un total de alrededor de diecisiete mil censistas.

23 Bertoni, 2001.

24 Hacia 1895, los Territorios patagónicos registraban muy importantes proporciones de población de origen chileno. El caso más notorio era el de Neuquén, donde según el censo de ese año el 61\% de la población era chilena. Segundo Censo de la República Argentina. 1895. Buenos Aires: Taller Tipográfico de la Penitenciaría Nacional, 1898, CLIII. 
que la desigual distribución geográfica del acelerado crecimiento demográfico profundizaba en el sistema federal. Como es bien conocido, el aumento de población se concentró en las regiones de mayor dinamismo económico, en particular en aquellas de producciones orientadas al sector exportador ${ }^{25}$. Esto no solo incrementó las asimetrías ya existentes entre las economías provinciales, que en opinión de algunos observadores exigían del Estado nacional un mayor auxilio hacia las menos aventajadas ${ }^{26}$, mientras que para otros esa asistencia entrañaba una grave amenaza al régimen federal, ya que aquellas, por su dependencia del presupuesto nacional, se convertían en instrumentos de una creciente centralización del poder ${ }^{27}$. En esos lazos de dependencia, algunos encontraban una de las principales causas de un aumento del poderío del Estado nacional que, según denunciaba alarmado Leandro N. Alem, uno de los protagonistas de la revolución de 1890 y fundador de la Unión Cívica Radical (UCR), producía una completa desnaturalización del federalismo argentino ${ }^{28}$. Pero además del desequilibrio que en este último generaban las desiguales capacidades económicas de las provincias, el muy dispar crecimiento demográfico experimentado por ellas introducía otro elemento de tensión en las instituciones representativas. El contraste entre la distribución de la población y la de las bancas en la Cámara de Diputados del Congreso de la Nación se volvía así más notorio, dado que la norma constitucional ordenaba que el número de escaños correspondiente a cada provincia debía guardar proporcionalidad con la cantidad de habitantes de cada distrito. El reconocimiento de esa falta de adecuación de las instituciones representativas a la nueva fisonomía de la sociedad argentina, que hacía aparecer a las primeras como un lastre que le impedía ulteriores progresos, condujo a diversos actores a entender que se había vuelto necesaria una reforma constitucional.

\section{REFORMAR LA CONSTITUCIÓN}

En junio de 1897, Lucas Ayarragaray ${ }^{29}$, diputado nacional por Entre Ríos, planteó al Congreso un proyecto de reforma de la Constitución por el que

\footnotetext{
25 Cortés Conde, 1979.

26 González, 1897.

27 Estrada, 1895.

28 Gallo, 2009.
}

29 Nacido en Paraná en 1861, Ayarragaray se graduó como médico en la Universidad de Buenos Aires y se incorporó al PAN formando parte de los sectores nucleados en torno al presidente Miguel Juárez Celman. La renuncia de este en 1890, llevó a Ayarragaray a reorientar su afinidad política hacia la figura de Carlos Pellegrini, quien asumió la presidencia de la 
proponía adecuarla a aquellas transformaciones, pero sin introducir en la misma cambios que implicaran riesgos para un orden político que no solo había hecho posible los progresos alcanzados, sino que además había demostrado su solidez tras las agitaciones revolucionarias que se habían sucedido desde comienzos de la década. Si bien afirmaba que «una constitución no es otra cosa que un instrumento de gobierno ${ }^{30}$, Ayarragaray creía conveniente emular el criterio conservador con el que entendía los ingleses operaban cambios en la suya. En consecuencia, solo se trataba de promover aquellas modificaciones que, exigidas por la evolución del país, no dieran lugar a «debates apasionados y extemporáneos que pudieran llevarnos a proceder con un criterio demasiado radical y avanzado ${ }^{31}$. De esta manera, su propuesta apuntaba a lograr un mejoramiento de la Constitución mediante una cantidad reducida de cambios. Entre los puntos más importantes destacaban el aumento del número de ministerios del Ejecutivo, y la revisión de la proporción entre población y representantes en base a la cual se formaba la Cámara de Diputados, una cuestión que no era nueva pero que había sido reactualizada por el censo de 1895. En anticipo a la oficialización de los resultados de este último, Ayarragaray juzgaba conveniente modificar la base demográfica vigente, para evitar así la formación de un cuerpo representativo demasiado numeroso y por tanto propenso a los excesos propios de las multitudes ${ }^{32}$. Según su planteo, también suscrito por quienes apoyaban la iniciativa, un excesivo aumento del número de bancas parlamentarias era enemigo de la adecuada representación política de la nación.

Pero los cambios que Ayarragaray proponía en materia de representación política iban más allá de una simple readecuación de la base poblacional conforme a la cual se asignaban diputados a cada uno de los distritos representados en el Congreso. Para el diputado entrerriano, la representación de los Territorios era «sumamente necesaria y conveniente» ${ }^{33}$, no solo porque daría a los pobladores de esas regiones una herramienta institucional para

nación hasta 1892, y a quien permaneció cercano hasta su muerte en 1906. Además de haber sido diputado nacional por las provincias de Entre Ríos (1891-1898) y Buenos Aires (19081912), Ayarragaray desempeñó funciones diplomáticas en Brasil, Italia y Suiza.

30 Diario de Sesiones de la Cámara de Diputados de la Nación (en adelante DSCD), 1897, 30 de junio, 194.

31 Idem.

32 Ibidem: 193. De aplicarse la proporción vigente a los resultados del censo de 1895, la Cámara de Diputados entonces integrada por 86 legisladores, habría pasado a estar formada por 193. En vísperas de iniciarse la convención reformadora, desde la prensa se seguía insistiendo en un abierto rechazo a esa posibilidad. La Nación, 24/2/1898; Tribuna, 24/2/1898.

33 Ibidem: 196. 
exponer sus intereses, sino también porque serviría para constituir una representación más completa de la nación. Según su opinión, al no haber sido adaptado a los profundos cambios producidos en el país desde el censo de 1869 , el sistema representativo había terminado dando lugar a una representación anacrónica de la nación, que constreñía su progreso a las formas institucionales de treinta años atrás. Por otro lado, la carencia de representación parlamentaria de los Territorios, que suponían casi la mitad de la extensión territorial de Argentina, parecía evidenciar las limitaciones del régimen político para producir la representación política del conjunto de la nación. La misma posibilidad de otorgar representación a las gobernaciones era contemplada como una forma de responder a las críticas que acusaban a ese régimen de oligárquico y por lo tanto de incapaz de producir una representación verdadera de la nación. Pero si tal medida permitiría subsanar, al menos en parte, aquel déficit de representación, en el caso particular de los Territorios se trataba además de afianzar un vínculo con la nación argentina que, se entendía, la conquista de los mismos no había logrado establecer por sí sola. Esa insuficiente integración de los Territorios a la vida nacional se buscaba subsanar, por un lado, mediante su representación en el Congreso y, por otro, a través de medidas que, como las aduanas libres que Ayarragaray proponía para las gobernaciones de la Patagonia, impulsaran un crecimiento económico y demográfico que estrecharía los lazos con el resto del país.

Pese a la eficacia persuasiva que podía tener el argumento de que la reforma se imponía como necesaria para adecuar las formas políticas del país a la nueva fisonomía de la sociedad, no todos los legisladores se mostraron de acuerdo con ese razonamiento. Las objeciones planteadas por algunos de ellos en parte tenían que ver con la denuncia de deficiencias técnicas en el levantamiento de los datos censales en 1895, que implicaban un subregistro de la población existente en algunas provincias. Pero las críticas más importantes apuntaban a las consecuencias que la revisión de las cuotas de representación asignadas a cada provincia tendrían para el orden político edificado a partir de la Constitución de 1853. Para Julio Astrada, diputado nacional por Córdoba — de la que había sido gobernador entre 1893 y 1895-, llevar adelante una redistribución de las bancas del Congreso en función de la distribución demográfica resultaba desaconsejable, porque al aumentar la representación de las provincias más pobladas, se rompería la «proporcionalidad» entre el litoral y el interior que, a su entender, había sido fundamental en la construcción del orden político entonces vigente. Entre otras cosas, sostenía Astrada, un cambio semejante daría a las provincias más pobladas la capacidad de elegir por sí solas al presidente, lo que volvería irrelevante el peso de las provincias menos beneficiadas por el crecimiento demográfico, todo lo cual 
suponía un escenario «atentatorio contra el régimen federal» ${ }^{34}$. La aprobación de los resultados del censo de 1895 y su adopción como base para distribuir la representación en Diputados, significaban para Astrada una «monstruosidad» que debía ser evitada. Aun cuando no dejaba de admitir que la profunda transformación demográfica del país era un hecho, creía posible «desviar sus resultados» por considerarlos una amenaza contra los «vitales intereses nacionales» ${ }^{35}$.

Argumentos como estos tuvieron sin embargo escaso apoyo entre los legisladores. En lo relativo a las deficiencias técnicas en la realización del censo de 1895, las respuestas apuntaron a señalar que nada de ello afectaba la validez de los resultados obtenidos, y que por lo tanto no había ningún motivo para impedir la revisión de la proporcionalidad entre población y representantes. Como señalaba Gaspar Ferrer ${ }^{36}$, también diputado por Córdoba, aún admitidas todas sus falencias, no podía dudarse que los resultados del censo de 1895 eran más ajustados a la realidad del país que los de 1869, en base a los cuales se mantenía todavía distribuida la cantidad de diputados por provincia $^{37}$. La idea de que los resultados del censo de 1895 ofrecían una imagen más precisa de la realidad nacional, no era solo defendida por legisladores de las provincias más beneficiadas por el crecimiento demográfico. A diferencia de los riesgos que Astrada entreveía en la revisión de la cantidad de diputados para cada provincia, Adolfo Dávila ${ }^{38}$, diputado por La Rioja - la segunda menos poblada del país-, entendía necesaria esa medida para «restablecer el equilibrio político de la nación», que había permanecido casi treinta años «sobre una base que importa el falseamiento del sistema representativo y federal» ${ }^{39}$. Por su parte, Ponciano Vivanco ${ }^{40}$, diputado por Córdo-

34 DSCD, 1897, 2 de agosto, 413.

35 Ibidem: 418.

36 Ferrer nació en Córdoba en 1854, donde también se graduó en derecho. Fue secretario de Roca cuando este cumplió funciones en Río Cuarto, y fue luego ministro de hacienda de Córdoba durante el gobierno de Julio Astrada. Desde temprano ligado al PAN, fue diputado nacional por Córdoba en tres ocasiones (1895-96, 1896-1900 y 1908-1912) y se desempeñó como juez federal en la Capital Federal entre su segundo y tercer mandato legislativo.

37 Ibidem: 414.

38 Nacido en Chilecito (La Rioja) en 1849, se sumó a la revolución encabezada por Mitre en 1874 y poco después se graduó en derecho en Buenos Aires. Además de ser varias veces legislador por La Rioja (en tres ocasiones como diputado y en dos como senador), se desempeñó durante más de veinte años en la redacción y dirección del diario porteño La Prensa, hacia el final del siglo XIX un firme opositor a Roca.

39 Ibidem: 416-417.

40 Nació en la localidad cordobesa de Bell Ville en 1865, se graduó en derecho en Córdoba. Ocupó el ministerio de hacienda de dicha provincia en el gobierno de Julio Astrada, y 
ba, descartaba que el reajuste de la representación a los datos del censo de 1895 implicara un riesgo para el régimen federal, en tanto que «el equilibrio político está mantenido por el senado» ${ }^{41}$, donde cada una de las provincias contaba con el mismo número de representantes.

Una semana más tarde, la comisión de asuntos constitucionales de la Cámara de Diputados produjo su despacho, que contenía algunos cambios respecto de la propuesta original. Mientras que el proyecto de Ayarragaray proponía la modificación de quince artículos constitucionales, la comisión decidió limitar los eventuales cambios a solo tres artículos: el $37^{\circ}$, que establecía la base demográfica por diputado nacional; el $67^{\circ}$ en su inciso primero, sobre el régimen de aduanas; y el $87^{\circ}$, relativo a los ministerios del Ejecutivo federal. En la exposición ofrecida en su calidad de miembro informante, Mariano de Vedia ${ }^{42}$, diputado por la Capital Federal, argumentaba que la comisión había seguido un prudente criterio conservador frente a la Constitución, considerada como un «depósito sagrado» que debía ser abierto lo menos posible y solo para introducirle enmiendas moderadas ${ }^{43}$. Según De Vedia, la proporcionalidad vigente entre población y diputados debía ser revisada para evitar el peligro de una deriva asambleísta del poder legislativo, de lo que la Revolución Francesa ofrecía experiencia ejemplar, pero además porque la formación de una legislatura de casi doscientos miembros era, en el caso de la República Argentina, «inconducente, inconveniente y onerosa» ${ }^{44}$. Pese a tales prevenciones, el despacho de la comisión proponía la formación de una convención de 193 miembros, que resultaban de aplicar a los resultados del censo de 1895 la proporcionalidad que regía desde 1853. Los legisladores que, como Astrada, se oponían al proyecto, subrayaban la incongruencia que suponía establecer una convención tan multitudinaria como el Congreso que se buscaba evitar ${ }^{45}$. Sin embargo, al informar el despacho a la cámara, De Vedia sostenía que los peligros de la condición multitudinaria que rechazaba para el Congre-

fue diputado nacional por la misma en tres ocasiones (1896-1900, 1900-1904 y 1906-1910). Ligado al roquismo, desde 1903 hasta 1908 fue también presidente del Consejo Nacional de Educación.

41 Ibidem: 419.

42 Nacido en 1867 en Buenos Aires, tuvo una profusa actividad periodística que lo llevó a formar parte de varios de los principales diarios porteños de la época y a convertirse en director de Tribuna, periódico estrechamente ligado al roquismo, con cuyo principal referente De Vedia cultivó una amistad personal. Fue diputado nacional por la Capital Federal entre 1896 y 1908, y en 1899 fue designado interventor de la provincia de Buenos Aires.

43 DSCD, 1897, 9 de agosto, p. 465.

44 Ibidem: 468.

45 Ibidem: 495. 
so no eran tales en el caso de la convención, ya que los poderes de esta última estarían limitados por la propia ley de reforma. Por un lado, al fijarse los artículos sobre los que podrían practicarse modificaciones y, por el otro, al dar a la convención un máximo de treinta días desde su constitución para resolver los puntos previstos.

Pero además de la magnitud de la convención, los cuestionamientos también iban dirigidos a poner en duda la legitimidad del Congreso para dar lugar a una reforma constitucional. Si algunos legisladores la entendían necesaria para superar el falseamiento de la representación que resultaba de mantenerla sobre los datos de 1869, otros diputados se servían de la misma inadecuación para sostener que un Congreso así conformado no podía habilitar el proceso de reforma constitucional. Como señalaba Dávila, la reforma correspondía de derecho «al pueblo argentino debidamente representado», y por lo tanto no a un Congreso que, debido a su falta de adecuación a la nueva demografía nacional, no representaba fielmente a dicho pueblo ${ }^{46}$. Esto significaba postular que primero era necesario formar un nuevo Congreso, ajustado a los datos del censo de 1895, y que solo después sería posible dar lugar al proceso de reforma constitucional ${ }^{47}$. A estos argumentos se añadían otros como los de Manuel Mantilla ${ }^{48}$, diputado por Corrientes, para quien el proyecto de reforma era inoportuno porque establecía que la elección de convencionales y las sesiones de la convención tendrían lugar en el primer trimestre de 1898, al calor de la competencia política por la Presidencia de la Nación. En una «democracia inorgánica» como Mantilla entendía era la argentina, convocar una convención en tales circunstancias implicaba el riesgo de que la reforma fuese hecha a medida de las conveniencias del partido gobernante:

en el seno de ella, trabarán lucha los partidos, obcecados por sus conveniencias, $\mathrm{y}$, cualquiera que sea la mayoría triunfante, hará una reforma partidista, no nacional; y habremos entrado en el camino que ha dado a Méjico un Porfirio Díaz, que no quiero, aunque traiga otro nombre, para mi patria ${ }^{49}$.

46 Ibidem: 480.

47 Todavía después de celebradas las elecciones para convencionales, desde La Prensa se insistía en que la reforma solo podía haber sido legítimamente autorizada por un Congreso adecuado al censo de 1895. La Prensa, 1/2/1898.

48 Nacido en Saladas (Corrientes) en 1853, se graduó en derecho en Buenos Aires. A raíz de los sucesos de 1890, participó en la organización de la Unión Cívica en Corrientes y poco después formó parte del sector radical que rompió con Mitre. Se involucró en la revolución radical de 1893, produciendo la caída del gobierno correntino. Fue diputado nacional por Corrientes en dos periodos (1880-1884 y 1894-1898), y fue senador por la misma entre 1898 y 1909.

49 Ibidem: 473. 
La referencia apuntaba al ex presidente Julio A. Roca, entonces senador por Tucumán y ya perfilado como favorito en la contienda presidencial en la que derrotaría a Bartolomé Mitre por un importante margen ${ }^{50}$. Más allá de estos argumentos, el proyecto de reforma constitucional fue aprobado por una amplia mayoría de los diputados.

Durante su tratamiento en el Senado, el proyecto tuvo algunas modificaciones que, sin embargo, no alteraron ni el momento de la reforma ni el limitado alcance de los cambios propuestos. El principal debate giró en torno a la cantidad de convencionales, como también a la modalidad de su elección. En base al despacho de la comisión de asuntos constitucionales de la Cámara, la mayoría de los senadores apoyó la iniciativa de reducir a 120 el número de convencionales. Según argumentaba Rafael Igarzábal ${ }^{51}$, representante por la Capital Federal, no solo se buscaba evitar los peligros propios de las asambleas multitudinarias, sino además establecer una representación al mismo tiempo democrática y federal, esto es, que no tuviera solamente en cuenta la cantidad de población de cada provincia, pero que tampoco diera a ellas paridad en el número de convencionales ${ }^{52}$. Mientras que la mayoría de los senadores acompañó la reducción de la cantidad de convencionales a 120, no hizo lo mismo con el sistema uninominal que el despacho de comisión sugería adoptar. De esa manera, la modalidad de elección de los convencionales se mantuvo ajustada al sistema de lista vigente para la elección de los diputados nacionales, en la que cada provincia constituía un distrito indiviso ${ }^{53}$. Pese a un nuevo intento de Diputados de elevar a 193 el número de convencionales, prevaleció el criterio del Senado, que insistió en la definitiva cifra de 120. Finalmente, el 20 de septiembre, el Congreso aprobó la ley 3.507, mediante la cual se abría el proceso de reforma de la Constitución nacional. Las elecciones para constituyentes quedaron fijadas para el 30 de enero de

50 Las elecciones presidenciales se celebraron el 10 de abril de 1898, resultando en 218 electores para Roca y 38 para Mitre, lo que dio al primero acceso a su segundo mandato presidencial. Cabe señalar, por otro lado, que tanto Roca como Mitre, entre otras destacadas figuras de la vida política de esos años, fueron también elegidos, ambos por la Capital Federal, como convencionales para la reforma de 1898.

51 Igarzábal nació en Córdoba en 1844. En 1872 fue elegido diputado por San Juan, y entre 1877 y 1886 fue senador por la misma provincia. En 1891 participó en el acuerdo entre Roca y Mitre, y fue senador por la Capital Federal entre 1892 y 1901. Hacia 1898, era el presidente del comité del PAN de tal ciudad.

52 Diario de Sesiones de la Cámara de Senadores 1897, 14 de septiembre, 279.

${ }^{53}$ Los 120 convencionales quedaron finalmente distribuidos de la siguiente manera: Capital Federal, 20; Buenos Aires, 28; Santa Fe, 12; Córdoba, 11; Entre Ríos, 9; Corrientes y Tucumán, 7 cada una; Santiago del Estero, 5; Salta y Mendoza, 4 cada una; San Luis, San Juan y Catamarca, 3 cada una; y La Rioja y Jujuy, con 2 cada una. 
1898, con el propósito de que las nuevas autoridades ejecutivas y legislativas de la nación surgieran con arreglo al nuevo texto constitucional.

\section{¿QUÉ HABITANTES CONTAR?}

La definición de las candidaturas se concretó pocos días antes de aquella fecha. La demora era señalada con preocupación por la prensa, ante la posibilidad de que quedara así comprometido el calendario electoral. Desde las páginas de La Nación y de Tribuna, se promovía la formación de listas integradas por candidatos de todos los partidos, con el propósito de asegurar, por un lado, que las principales notabilidades de cada fuerza estuvieran presentes, y de evitar, por otra parte, que las pasiones suscitadas por la competencia electoral afectasen las deliberaciones de la convención. De esta manera, en la Capital Federal, la Unión Cívica Nacional (UCN), el PAN y la UCR - excepto el sector radical anticoalicionista-, acordaron una lista tripartita con el mismo número de candidatos para cada partido. Estos acuerdos, como el hecho de que no había cargos ejecutivos o legislativos en disputa, explican en parte la modesta concurrencia de los ciudadanos a las urnas, lo que también obedeció a que la opinión pública se hallaba más atenta a las tensiones con Chile y a la situación política de la provincia de Buenos Aires, donde el PAN y la UCR trabajaban en un acuerdo por la gobernación ${ }^{54}$. Si La Nación y Tribuna se lamentaban de esa baja participación electoral, en la que encontraban testimonio de una educación cívica todavía insuficiente, La Prensa la interpretaba como un «plebiscito negativo» que privaba de legitimidad a la convención ${ }^{55}$. De cualquier manera, el proceso de reforma continuó adelante y los convencionales electos comenzaron a reunirse en la Capital Federal a partir del 24 de febrero, aunque sin lograr quórum hasta el 2 de marzo, cuando la convención inició sus sesiones ordinarias.

La primera cuestión abordada por los convencionales fue la de la modificación de la base demográfica para la conformación de la Cámara de Diputados, que se proponía establecer en 33.000 habitantes o fracción no inferior a 16.500. Como ya había sido planteado durante la discusión de la ley de reforma, se buscaba evitar la formación de un Congreso demasiado numeroso que se consideraba una inconveniencia política al mismo tiempo que un in-

54 En la Capital Federal asistieron más de 10.500 votantes sobre una cantidad de 35.000 registrados, lo que en la mirada de Tribuna no era del todo insignificante, dado el objeto de la elección y el carácter voluntario del sufragio. Tribuna, 31/3/1898.

55 La Nación, 31/1/1898; Tribuna, 2/2/1898; La Prensa, 2/2/1898. 
necesario aumento del gasto público. A esas razones ya expuestas en 1897, Ayarragaray añadía, ahora como convencional por Entre Ríos, la observación de que, a diferencia de otras naciones donde la mejora de la representación podía pasar por el aumento de la magnitud de los parlamentos, nada de eso era necesario en Argentina, porque las diferencias de los partidos «son más nominales que reales, pues proclaman los mismos principios e inscriben en su programa los mismos propósitos» ${ }^{56}$.

La propuesta de fijar en 33.000 la cantidad de habitantes por diputado nacional despertó críticas, sobre todo por parte de los convencionales electos por provincias que podían verse perjudicadas con esa nueva proporción. De aplicarse a los resultados del censo de 1985, la fórmula suponía la pérdida de una diputación para Catamarca y de dos para Santiago del Estero. Por tal motivo, Manuel Sibilat Fernández, convencional por esta última, solicitó - sin éxito - la incorporación de alguna cláusula que impidiera la reducción del número de diputados nacionales con que hasta entonces contaba cada una de las provincias ${ }^{57}$. Por supuesto, el interés por evitar la disminución del peso parlamentario de las provincias menos pobladas constituía una evidente motivación de sus representantes en la convención. Pero la posibilidad de influir en las decisiones de esta última, dependía de persuadir a la mayoría de los convencionales con argumentos que remitiesen a cuestiones más amplias que la situación particular de una provincia, y a los que los demás miembros de la convención se vieron obligados a contestar. De tal manera, los debates librados en torno al tema de la proporcionalidad entre población y representantes implicaron discusiones conceptuales más problemáticas, que condujeron a abordar no solo la definición de una cantidad de habitantes, sino también el sentido atribuido a esta noción.

Fue Silvano Bores ${ }^{58}$, convencional por Tucumán, quien abrió el debate en torno a esos aspectos conceptuales. Si bien no ponía en duda que los profundos cambios experimentados por el país obligaban a introducir ajustes en el texto constitucional, entendía que la reforma encarada debía ser capaz de preservar el espíritu de una Constitución bajo cuyo amparo se había logrado duplicar la población, consolidar el dominio territorial, esta-

56 República Argentina, Convención Nacional de 1898, Buenos Aires, Compañía Sud-Americana de Billetes de Banco, 1898, 41.

57 Ibidem: 84.

58 Nacido en Tucumán en 1855, fue diputado nacional por dicha provincia hasta 1880 , cuando Roca lo designó subsecretario de Relaciones Exteriores, hasta que en 1883 fue nombrado embajador en Bolivia. Participó de la revolución tucumana de 1887 que derrocó al gobernador Juan Posse, y entre 1890 y 1894 fue gobernador de dicha provincia. Entre 1898 y 1906 se mantuvo como diputado nacional por Tucumán. 
blecer el orden interno, extender la civilización y aumentar la riqueza del país. Los cambios debían estar entonces orientados a mantener esas conquistas gracias a las cuales «la unidad política y civil ha sido completada por la económica», dando lugar a «la solidaridad de un común destino» ${ }^{59}$. La reforma constitucional debía así servir al reforzamiento de la unidad nacional, trabajosamente alcanzada en el curso de las décadas previas, pero en el fin de siglo enfrentada a los nuevos desafíos derivados del poderoso flujo inmigratorio que impulsaba el acelerado crecimiento demográfico del país. De esta manera, las argumentaciones de Bores no apuntaban tanto a la cuestión de la proporción entre población y representantes, sino más radicalmente a precisar cuál era la población que se debía tomar en cuenta para producir el reparto de los escaños.

Para Bores, los constituyentes de 1853 habían debido elaborar una Constitución para un país desierto. Había sido la urgencia de poblarlo la que los condujo a abrir las puertas a la población extranjera, ofreciendo a esta un amplio abanico de libertades y garantías. Pero según Bores los constituyentes nunca habían concebido a esa población como perteneciente al pueblo de la nación. Bien entendido este principio, señalaba, la Constitución «venía a establecer que el pueblo tuviera una representación según el número de habitantes nacionales, porque el elemento extranjero era casi desconocido» ${ }^{60}$. Permanecer fieles al espíritu de los constituyentes de 1853 exigía entonces entender que no era la población a secas la que se debía tomar como base para determinar la cantidad de diputados correspondientes a cada provincia, sino la población argentina en forma exclusiva. Todavía más, si la Cámara de Diputados debía consagrar la representación del pueblo de la nación, la asignación de bancas a cada provincia no debía hacerse incluyendo a los extranjeros, que además de mostrarse poco dispuestos a adoptar la nacionalidad argentina no eran tampoco instados a ello por la legislación del país. Mientras el extranjero no se convertía en un verdadero habitante mediante la adopción de la nacionalidad argentina, permanecía como un mero residente, es decir, como alguien que se encontraba de paso por el país. Según sostenía Bores, a partir de tales premisas resultaba «imposible llegar a otro término distinto de la exclusión del extranjero como número político para fijar la base de la representación» ${ }^{61}$. En tanto no fuera resuelto el problema de la naturalización de los extranjeros y estos permanecieran como un conjunto ajeno al pueblo de la nación, lo más aconsejable era,
59 Ibidem: 43.
60 Ibidem: 45.
61 Ibidem: 55. 
según planteaba Bores a los demás convencionales, que «seamos nosotros los únicos dueños de casa» ${ }^{62}$.

En apoyo a esta posición, el también convencional por Tucumán Armando Zavaleta sostenía, invocando la autoridad de juristas norteamericanos como Paschal y Kent, que uno de los problemas que afectaban más seriamente a la República derivaba de que había sido «tergiversado el verdadero sentido de la palabra habitante», que en su acepción constitucional no remitía a todos los residentes en el territorio argentino, «sino a aquéllos que encerraban en sí la capacidad de la nacionalidad o que la habían adquirido por la naturalización» ${ }^{63}$. Dado que «pueblo es la entidad política que abraza el concepto de la nacionalidad», la formación de la Cámara de Diputados, cuya función era concretar la representación de aquel soberano, exigía que solo fuera contabilizada la población argentina de cada una de las provincias ${ }^{64}$. Era el conjunto de los ciudadanos, que lo eran por su nacionalidad argentina, el único que verdaderamente formaba el pueblo a representar por la Cámara de Diputados, por lo cual los extranjeros no debían ser considerados para calcular el número de escaños asignado a cada provincia. Según Zavaleta, esto no suponía privar a los extranjeros de toda representación, dado que disponían de ella en el Senado. No porque existiera allí alguna representación especial para la población extranjera, sino porque «el senado, que representa a cada uno de los estados federales, comprende a toda su fuerza viva, a todo lo que está dentro de sus límites, incluso los extranjeros ${ }^{65}$. De esta manera, si bien Zavaleta difería con Bores en la base demográfica que cada uno consideraba más apropiada -25.000 el primero y 33.000 el segundo-, ambos coincidían en que solo se debía computar a la población argentina. Mantener el criterio, por ambos juzgado equívoco, de incluir a la población extranjera en aquella base que no solo determinaba el número de diputados nacionales por provincia, sino que además incidía sobre la cifra de electores presidenciales de cada una, quebrantaría el equilibrio político del régimen federal y hasta podría llevar a que el presidente fuese, alertaba Bores, elegido «por los votos de una o dos provincias que tuvieran una población extranjera superior a la propia población nacional, dejando así a la inmensa mayoría argentina sin influencia efectiva en el gobierno de su propia casa» ${ }^{66}$.

Lejos de encontrar respaldo en la esfera pública, esos argumentos encontraron un abierto rechazo de los diarios que cubrían el desarrollo de la con-

\footnotetext{
62 Ibidem: 58.

63 Ibidem: 75.

64 Idem.

65 Ibidem: 76.

66 Ibidem: 57.
} 
vención. Para La Nación, se trataba de una idea inspirada en un «criollismo exagerado e inútil», y La Prensa calificaba la propuesta como «de índole acomodaticia o caprichosa» ${ }^{67}$. También Tribuna, más afín a los círculos del roquismo, comentaba que el de Bores había sido un «bellísimo discurso», pero para expresar enseguida su desaprobación señalando que, al discutir temas ajenos a la ley de reforma, la convención incurría en un extravío revolucionario $^{68}$. La opinión de la amplia mayoría de los convencionales era también contraria a razonamientos como los de Bores. No solo ocurría, según Ayarragaray, que «el concepto de la palabra habitante está perfectamente fijado hace mucho tiempo» ${ }^{69}$. A su entender, la idea de que tal noción comprendía tanto a la población argentina como a la extranjera se encontraba sólidamente arraigada, tanto en la tradición constitucional del país, como en la propia experiencia histórica de una nación que había alcanzado el progreso gracias al aporte de esa población foránea. Aceptar propuestas como las de Bores y Zavaleta significaría, afirmaba Ayarragaray, «un movimiento reaccionario en la política liberal argentina», porque «gracias a la incorporación del extranjero hemos cambiado no solo de índole sino también de destino; gracias a este concurso que han asegurado nuestras leyes, hemos concluido con el desierto y la barbarie $\rangle^{70}$. Por su parte, Gabriel Carrasco, convencional por Santa Fe y uno de los responsables de la dirección del censo de $1895^{71}$, comentaba que todas las constituciones del mundo tenían a la población general como la base de sus sistemas representativos, pero que en el caso de la Argentina, donde el extranjero formaba parte de todos los aspectos de la vida colectiva, era tanto más necesario «que mantengamos en nuestra ley fundamental la hermosa base de la democracia: la población ${ }^{72}$. Más lejos aún iba José Miguel Guastavi$\mathrm{no}^{73}$, convencional por Corrientes, para quien los extranjeros formaban parte

67 La Nación, 5/3/1898; La Prensa, 6/3/1898.

68 Tribuna, $5 / 3 / 1898$.

69 Ibidem: 47.

70 Ibidem: 59.

71 Nacido en Rosario en 1854, se graduó en derecho en Santa Fe, fue luego intendente de su localidad natal y más tarde diputado provincial. Además de su labor como director de censos, tanto en su provincia como en la órbita nacional, fue fundador de la Oficina Demográfica Argentina y fue también incorporado a la Sociedad Geográfica de Madrid. Desde Tribuna se atribuía a Carrasco la recomendación de fijar la proporción de un diputado cada 33.000 habitantes. Tribuna, 6/1/1898.

72 Ibidem: 63.

73 Nacido en Corrientes en 1838, se graduó en derecho en Córdoba y en 1863 se convirtió en el primer secretario de la Corte Suprema de Justicia. Participó en la Guerra del Paraguay y en 1868 fue elegido gobernador de Corrientes. Fue además elegido diputado nacional por dicha provincia en 1872, 1880 y 1896. 
del pueblo argentino, que no se reducía a la población nacional porque estaba «en la comunicación de las razas, en el comercio de las ideas, en el comercio real de los artefactos; está en el extranjero y en el ciudadano, en el hombre y en la mujer, en el niño y en el anciano» ${ }^{74}$.

Argumentos como los desplegados por Bores y Zavaleta podrían ser interpretados como simples intentos, de antemano perdidosos, por obstruir todo lo posible un aumento de la base demográfica de representación que perjudicara a las provincias menos pobladas. Aún si esa podía ser la motivación más directa, los razonamientos de esos convencionales expresaban importantes preocupaciones también compartidas por más amplios círculos políticos e intelectuales del fin de siglo. Entre estas, la pregunta acerca de cuál era el verdadero pueblo argentino y quiénes formaban verdaderamente parte de él, resultaba especialmente acuciante en una época marcada por el fenómeno inmigratorio, y en una coyuntura signada por la aparición de asociaciones nacionalistas como la Liga Patriótica Argentina (Bertoni, 2001: 239), organizada mientras tenía lugar la convención reformadora. Para quienes frente a tal escenario era imperativo asegurar la genuina representación política del pueblo, la cuestión no se agotaba en la exclusión de la población extranjera de la base demográfica conforme a la que debían asignarse diputados y electores a cada provincia. También involucraba la cuestión del estatus de aquellos espacios que, pese a constituir casi la mitad de la extensión geográfica de la nación, no contaban con ninguna representación.

\section{El LUGAR DE LOS TERRITORIOS}

Aun cuando el único punto relativo a los Territorios en la ley de reforma era el de la supresión de aduanas en las gobernaciones patagónicas, la cuestión de la representación de dichos espacios constituyó otro de los asuntos abordados por la convención. Para varios de sus miembros, los Territorios constituían porciones del suelo argentino que se encontraban injustamente privadas de representación. Si la Cámara de Diputados era la institución que debía representar al pueblo de la nación, el hecho de que los Territorios no tuvieran parte en ella ponía en evidencia, para quienes así lo veían, el carácter incompleto de esa representación. En la medida que allí no había representantes por las porciones del pueblo argentino presentes en los Territorios, era posible entender que la República estaba sostenida en una representación parcial de

\footnotetext{
74 Ibidem: 79.
} 
la nación, o bien, más radicalmente, que los pobladores de aquellas gobernaciones en realidad no eran considerados miembros del pueblo argentino. La idea de que la condición institucional de los Territorios expresaba un déficit de representación no suponía ninguna novedad hacia 1898, sino que se remontaba a la propia creación de las gobernaciones ${ }^{75}$. Un tema frecuente en torno a los Territorios era que su representación en el Congreso era necesaria para que esas regiones pudieran informar sus necesidades a los legisladores, para obtener así medidas que impulsaran en forma más efectiva un progreso que hacia finales del siglo XIX parecía allí menos portentoso de lo inicialmente imaginado. Empero, en un clima finisecular en el que la cuestión nacional cobraba más relevancia, la incorporación de los Territorios al Congreso aparecía en ciertas miradas - como la de Ayarragaray, quien la había incluido en su proyecto de reforma constitucional de 1897- como una medida necesaria para lograr una completa representación política de la nación.

No resulta casual que fueran los convencionales que proponían restringir la base de representación a la población argentina, quienes más insistieran en incorporar a los Territorios en el Congreso. En la mirada de Bores, ambas medidas eran necesarias para asegurar una genuina representación del pueblo de la nación, del que no tenía duda también formaban parte los habitantes de los Territorios. A su entender, era justo

que el habitante del territorio nacional deje de ser un desterrado dentro de su propia patria por olvido de la Constitución. No responde a ningún principio de equidad darle las cargas sin los beneficios de la ciudadanía. Habita el territorio y forma parte del pueblo, sujeto a todas las requisiciones de las leyes, y si no es el miembro de un estado, lo es de la nación. [...] Saquémosle del limbo, veámosle la cara, escuchémosle y que venga, como todos los miembros de la familia argentina, a ocupar su sitio en la vida pública, como lo tiene en la guardia nacional, en los padrones de contribución o en los libros de los registros civiles ${ }^{76}$.

La extensión de la cita se justifica por el modo en que resume el argumento desde el que Bores proponía dar diputados a los Territorios, pero también por la forma en que todo ello se relacionaba con su particular concepción del habitante. Como fue señalado, Bores entendía esta condición como privativa del argentino, fuese nativo o naturalizado. Esto significaba pensar a la noción de habitante como equivalente a la de ciudadano, abandonando el criterio de concebirlas como condiciones jurídicas diferentes, al modo de la clásica dis-

75 Sobre las razones que llevaron a que la ley de Territorios no contemplara la representación de estos espacios, Gallucci, 2015 y 2016.

76 Convención..., 58. 
tinción de Alberdi ${ }^{77}$. Era a partir de esa sinonimia que Bores podía por un lado plantear la exclusión de la población extranjera de la base demográfica de representación, mientras por otro proponía incorporar al Congreso diputados por los Territorios. Tan radical redefinición del concepto de habitante no contaba con respaldo en la tradición constitucional argentina, ni en la mayoría de los convencionales, ni en la opinión de la prensa. Pero, ¿cómo pensaron entonces la condición de los Territorios quienes se mantuvieron fieles a la diferencia entre las categorías de habitante y de ciudadano?

Algunos, como Honorio Leguizamón ${ }^{78}$, convencional por Entre Ríos, proponían incluir a los Territorios en las elecciones de diputados nacionales, a razón de un representante por cada 33.000 habitantes o fracción no menor a 16.500, entre los que contarían tanto argentinos como extranjeros ${ }^{79}$. Dado que los diputados representaban al pueblo argentino y que parte de este se hallaba en los Territorios, estos también debían contar con sus propios diputados $^{80}$. Sin embargo, otros convencionales se pronunciaron en contra de la posibilidad de otorgar representación a los Territorios, ya fuera en la forma de delegados sin voto o en la de diputados de plenas facultades. No solo ocurría que la cuestión del estatus político de los Territorios estaba fuera del alcance explícitamente delimitado por la ley que abrió camino a la reforma constitucional, como algunos convencionales se ocuparon de recordar ${ }^{81}$. Los intentos por lograr que la convención se saliera de los límites impuestos en la ley de reforma no torcieron el criterio, como ya se señaló ampliamente mayoritario, de que los cambios a introducir en la Constitución debían ser los mínimos e indispensables. Pero más allá de obstáculos legales o de la prudencia con que los convencionales entendían necesario actuar, las razones de que no se diera lugar a la representación parlamentaria de los Territorios respondían a la caracterización que hacían de esos espacios.

77 Botana, 1997.

78 Hermano de Onésimo - ministro de Justicia en el gobierno de Nicolás Avellaneda, miembro de la Corte Suprema entre 1877 y 1882, y varias veces diputado nacional por Entre Ríos-, nació en Concordia en 1848 y se graduó como médico en Buenos Aires. Fue docente y rector del Colegio Nacional de Concepción del Uruguay, y entre 1889 y 1893 dirigió la Escuela Normal de Profesores de Buenos Aires. Fue también uno de los fundadores del Instituto Geográfico Argentino, institución con especial interés en los Territorios Nacionales.

79 Convención..., 64.

80 Ibidem: 66.

81 Ibidem: 45. El mismo criterio se mantuvo ante una petición que un grupo de pobladores del Territorio de Misiones dirigió a la convención para solicitar que se diera representación en el Congreso a las gobernaciones federales. 
Fue sobre todo durante el debate en torno a la posibilidad de establecer aduanas libres en los puertos patagónicos cuando los convencionales ofrecieron sus miradas acerca de la condición del conjunto de las gobernaciones. Una imagen entonces muy extendida mostraba a los Territorios como espacios que, luego de su efectiva incorporación al dominio nacional, habían sido dejados a su suerte, alcanzando solo modestos progresos que se reflejaban en su escasa población. Ese retrato no solo circulaba al interior de las dirigencias políticas de la época, sino también en la opinión pública, como ocurría con las descripciones que, de manera casi simultánea a la convención reformadora, Roberto Payró ofrecía en sus notas de viaje publicadas en las páginas de La Nación - poco después reunidas bajo el título de La Australia argentina (1898) - , pero como también era el caso de otras publicaciones periódicas de relevancia ${ }^{82}$. De modo coincidente con ese cuadro de general desamparo, figuras como Juan Balestra, convencional por Corrientes y gobernador de Misiones entre 1893 y $1896^{83}$, se referían a las gobernaciones como «completamente abandonadas», como «pobres territorios que no tienen quien haga oír su voz en la cámara de diputados, ni en el senado, ni quien los represente en la Convención ${ }^{84}$. Según Balestra, promover el progreso e integración a la vida nacional constituía una necesidad común a todos los Territorios y no solo a los de la Patagonia, por lo cual acompañó a otros convencionales que proponían hacer extensiva a todas las gobernaciones la creación de puertos libres. Sin embargo, la convención finalmente decidió no innovar sobre este punto de tan complejas implicancias sobre el régimen aduanero.

Pero más allá de las acusaciones hechas contra las anteriores administraciones, la mayoría de los convencionales no parecía todavía ver en ninguno de los Territorios una entidad que mereciera representación política. Por ejemplo, Wenceslao Pacheco ${ }^{85}$, convencional por Mendoza, argumentaba que «un territorio no es una autonomía; no hay en él soberanía local, ni gobernador, ni legislatura, ni poder judicial, no hay tendencias ni pasiones políticas», por lo que en definitiva era «una zona innominada, gobernada absolutamente por

${ }^{82}$ La Prensa, 21/11/1897; Tribuna, 11/3/1898.

83 Además de dichos cargos, Balestra, nacido en Goya en 1861, fue ministro de Justicia e Instrucción Pública durante la presidencia de Pellegrini, y en cuatro oportunidades resultó elegido diputado nacional por Corrientes (1888, 1898, 1902 y 1906).

84 Ibidem: 134-135.

85 Nacido en Mendoza en 1838, asistió al Colegio Nacional de Concepción del Uruguay y se graduó en derecho en la Universidad de Buenos Aires. Fue ministro de Hacienda en el gobierno de Roca y durante la presidencia de Juárez Celman fue titular de Hacienda y del Interior. 
el pueblo de la nación, por medio de sus representantes» ${ }^{86}$. Una imagen similar de las gobernaciones era sostenida por Ferrer, quien las describía como «territorios despoblados, desiertos» ${ }^{87}$, mientras que Carrasco se refería también a las gobernaciones como «vastos territorios, fértiles en parte [y] despoblados casi por completo» ${ }^{88}$. Aun cuando no se dejaba de reconocer que en los Territorios había alguna población, su magnitud era juzgada mínima en relación con la vastedad de aquellos espacios, lo que hacía que no se abandonara su caracterización como desiertos. En efecto, si el último censo había registrado una población de 10.422 habitantes en Chaco, nada impedía a Carrasco sostener que dicho Territorio "es todavía un problema de la civilización, y es uno de nuestros más grandes aunque hermosos desiertos» ${ }^{89}$. Pero por sobre todas las cosas, el carácter de artificio administrativo de los Territorios hacía que la existencia de población no fuera en sí misma considerada indicativa de la presencia de una entidad social plausible de representación política. Acerca de La Pampa, cuya población se calculaba en 25.914 habitantes hacia 1895, Pacheco afirmaba que «no es más que una prolongación de las provincias de Buenos Aires, Córdoba y San Luis $\rangle^{90}$.

Sería equivocado interpretar que, al sostener que los Territorios eran simples divisiones creadas para administrar esos espacios de reciente incorporación al dominio nacional, no se hacía más que ofrecer justificaciones para mantener restringidos los derechos políticos de los habitantes de aquellos espacios, por considerar que no contaban con la capacidad política necesaria para gozar de una ciudadanía plena. Algunos convencionales, como Benjamín Figueroa ${ }^{91}$, por Salta, podían sostener acerca de los Territorios que «no es exacto que no tengan intereses políticos y comerciales, que no formen un núcleo con cierta capacidad política», pero de allí no derivaba la necesidad de ninguna inmediata equiparación con las provincias; por el contrario, recordaba que la ley vigente en la materia establecía «que cuando lleguen a contar sesenta mil habitantes, pueden sus moradores gestionar que el territorio sea erigido en estado federal independiente, como los demás que arrancan su
86 Ibidem: 100.
87 Ibidem: 111.
88 Ibidem: 119.
89 Ibidem: 121.
90 Ibidem: 125.

91 Nació en Salta en 1849 y veinte años más tarde se graduó como abogado en Buenos Aires. Desempeñó cargos en la justicia provincial de Salta, por la que fue elegido senador nacional en 1889. En 1892 fue designado embajador en Bolivia y sus vínculos con el roquismo lo llevaron a ser nombrado interventor en La Rioja, en Santiago del Estero y en Catamarca. 
existencia de la Constitución $»^{92}$. Aún los escasos convencionales que como Figueroa llegaban a ver en los Territorios «cierta capacidad política», entendían que esta no era todavía suficiente para reconocerlos como nuevas provincias. De esto último estaban por supuesto convencidos aquellos que, además de contemplar esos espacios como vastos despoblados, desestimaban la posibilidad de otorgar a los mismos representación en el Congreso. Como expresaba Carrasco, no había que innovar al respecto porque «la ley que rige los territorios ya ha sido bastante previsora, y establece en uno de sus artículos que, cuando ellos lleguen a tener 60.000 habitantes, podrán figurar como provincias $\rangle^{93}$.

Más allá de los diagnósticos que podían hacerse acerca del estado social de las gobernaciones federales, lo importante es advertir que unos y otros no solo compartían la idea de que aquellas debían dar lugar a nuevas provincias, sino además que esa transformación podía hacerse efectiva en base a un criterio que, como el establecido en la ley de Territorios de 1884, solo consistía en una mera cantidad de población, sin distinción de nacionalidad ni de capacidad política. De esta manera, al descartar la posibilidad de otorgar representación parlamentaria a los Territorios, los convencionales no buscaban restringir los derechos de los escasos pobladores de tales espacios mediante espurios tecnicismos legales que mal habrían escondido esa motivación ${ }^{94}$. Lejos de contemplar a los ciudadanos de los Territorios como políticamente incapaces, los convencionales procedían con el mismo criterio conservador que los había llevado a mantener a la población extranjera incluida en la base demográfica de representación, inclinándose a preservar también la representación parlamentaria como un atributo exclusivo de una calidad provincial que las gobernaciones no tenían, pero que habrían de alcanzar. Como se sostenía desde las páginas de Tribuna, «los territorios son provincias en formación [y] algunos están muy cerca de alcanzar ese destino» ${ }^{95}$.

\section{CONCLUSIONES}

La convención concluyó el 15 de marzo, aprobando los cambios que introducía en la Constitución. Por una parte, fijó en ocho el número de ministerios del Ejecutivo nacional y, por otra, modificó la proporción entre pobla-

\footnotetext{
92 Ibidem: 103-104.

93 Ibidem: 60.

94 Favaro y Arias Bucciarelli, 1995: 24. Ruffini, 2007: 124-125.

95 Tribuna, 14/3/1898.
} 
ción y representantes, estableciéndola en un diputado cada 33.000 habitantes o fracción no inferior a 16.500. La Cámara de Diputados pasó así a estar formada por 120 legisladores, mientras que el Colegio Electoral, constituido por una cantidad de escaños igual al doble del número de diputados y senadores de cada uno de los quince distritos con representación parlamentaria, pasó de 232 a 300 integrantes. No hubo cambios para los Territorios, que pese a lo propuesto en el proyecto original de Ayarragaray y a las razones expuestas por Bores durante la convención, permanecieron sin representación en el Congreso ni participación en el Colegio Electoral.

Los cambios operados parecieron confirmar los temores de algunos miembros de la convención acerca la posibilidad de que, aumentado por la población extranjera el peso de ciertas provincias en el Colegio Electoral, unas pocas de ellas pudieran imponer a las demás una fórmula presidencial. En efecto, la Capital Federal, Buenos Aires, Santa Fe y Entre Ríos habían pasado a reunir 152 votos electorales, alcanzando así la mayoría absoluta en el Colegio ${ }^{96}$. Pero las elecciones celebradas el 10 de abril, en las que Roca obtuvo un amplio triunfo, convirtiéndose en el primero en ocupar en dos oportunidades la presidencia de la República, estuvieron lejos de ser la confirmación de aquellas aprensiones. En efecto, el contundente triunfo de Roca se nutrió de votos electorales cosechados en todos los distritos, haciendo que aquella posibilidad apareciera como una mera especulación. La hipótesis de que un pequeño grupo de provincias, coaligadas en torno a un también hipotético interés común, podría en lo sucesivo imponer al presidente de la República, no pasó de ser un ejercicio especulativo ${ }^{97}$.

Claro que no es válido descartar como infundados los peligros que algunos actores podían vislumbrar en los modos en que las instituciones representativas eran ajustadas a las aceleradas transformaciones que el país experimentaba. Se trata de advertir, en cambio, que las provincias estaban lejos de constituir actores políticos que, guiados por intereses perfectamente definidos, habrían sido capaces de coaligarse con otros pares de igualmente nítidas motivaciones. En este sentido, en lugar de entender a las provincias como actores a los que sería

96 Como resultado de la reforma, la Capital Federal pasó de 9 a 20 diputados nacionales; la provincia de Buenos Aires, de 16 a 28; Santa Fe, de 4 a 12; Entre Ríos, de 7 a 9; Corrientes, de 6 a 7; Tucumán, de 5 a 7; y Mendoza, de 3 a 4. En cambio, Santiago del Estero redujo su representación de 7 a 5 diputados, mientras que Catamarca lo hizo de 4 a 3 . No hubo variaciones para las demás provincias.

97 Tal distribución regional de los votos electorales tampoco se registró en las elecciones celebradas en 1904 y en 1910, en las que triunfaron Manuel Quintana y Roque Sáenz Peña respectivamente. 
posible atribuir bien definidos intereses ${ }^{98}$, parece más provechoso concebirlas como escenarios donde se desenvolvía una vida política en la que esos intereses eran más objetos de disputa que algo asumido como común por todos los miembros de los círculos dirigentes de una misma provincia. Inclusive en las décadas finales del siglo XIX, las provincias constituyeron espacios atravesados por rivalidades políticas muchas veces intensas, y al mismo tiempo continuaron operando como escenarios estructuradores de una vida política que se mantuvo condicionada por un régimen federal ${ }^{99}$. Esto no significa pensar a partir de una definición que conduzca a sostener, por ejemplo, que el de la Argentina del cambio de siglo era un federalismo «restrictivo» sustentado en un control casi vertical de las autoridades nacionales sobre las provincias ${ }^{100}$; sino entender que lo que suele ser descrito como una progresiva imposición de un abstracto «Estado central» sobre las provincias, era en realidad expresión de una sofisticada arquitectura política capaz de hacer frente, dentro de un siempre limitado abanico de posibilidades, a las cada vez más notorias disparidades existentes entre dichas entidades. En un sentido similar al señalado por algunos estudios recientes ${ }^{101}$, parece posible entender que federalismo y centralización no eran elementos naturalmente excluyentes, sino rasgos de un orden político que podían presentar múltiples articulaciones.

En 1898, la Revista de Derecho, Historia y Letras publicó una carta en la que Manuel D. Pizarro, ministro de Roca durante su primera presidencia pero más tarde un firme opositor a este, dictaminaba que el federalismo argentino estaba muerto y que, por lo tanto, la Constitución debía ser adaptada a la fisonomía unitaria que el país había adquirido ${ }^{102}$. También la prensa, especialmente aquella opuesta al roquismo, ofrecía diagnósticos no menos lúgubres sobre el estado de ese régimen federal. Desde La Prensa, por ejemplo, se aseveraba que la degradación del federalismo argentino era tal que «la entidad provincial ha desaparecido» ${ }^{103}$. Los indicios recogidos al examinar la convención de 1898, sin embargo, invitan a tomar con prudencia tales testimonios. En primer lugar, porque ninguno de los convencionales llegó a formular argumentos extremos como los de Pizarro, a quien algunos periódicos atribuían la idea de excluir a los extranjeros de la base demográfica de representación ${ }^{104}$.

\footnotetext{
98 Gibson y Falleti, 2007.

99 Alonso y Bragoni, 2015.

100 Botana, 1993.

101 Alonso, 2015.

102 Pizarro, 1898.

103 La Prensa, 1/2/1898.

104 La Nación, 13/1/1898.
} 
Pero sobre todo porque, en segundo término, el desarrollo de la convención sugiere que la entidad provincial estaba lejos de haber pedido toda consistencia. Como pudo verse, los convencionales buscaron, de forma previsible, que los cambios introducidos al texto constitucional fueran lo menos desventajosos para sus provincias. Pero más importante que esto resulta advertir que las resoluciones que tomaron sobre las propuestas y peticiones relativas a los Territorios, demuestran que cuestiones relevantes del sistema federal, tales como la representación en el Congreso nacional, seguían siendo concebidas como indisociables de la calidad provincial. No solo se trataba de que los convencionales de 1898, como varias décadas más tarde explicaría un estudioso del orden legal de tales espacios, habían procedido conforme a «la buena doctrina constitucional que establece que las convenciones reformadoras solo poseen poderes limitados» ${ }^{105}$. La cuestión primordial radicaba en que la concesión de representación parlamentaria a unidades carentes de entidad provincial implicaba, para la amplia mayoría de los convencionales, un radical distanciamiento respecto de los principios consagrados en una Constitución que se proponían conservar, aún al introducirle modificaciones. Del mismo modo que decidieron mantener a los extranjeros dentro de la base demográfica conforme a la cual debía determinarse el número de diputados asignados a cada provincia, también resolvieron preservar la calidad provincial como fundamento de la representación en el Congreso nacional.

El examen de la reforma constitucional de 1898 permite advertir que aun cuando un amplio y heterogéneo conjunto de actores denunciaba una degradación del régimen federal, el sistema representativo permanecía organizado sobre principios federales acaso más sólidos de lo que un enfoque habitual parece sugerir. Solo al ampliar la mirada hasta considerar también a los Territorios se vuelve posible advertir que la calidad misma de provincia constituía uno de los pilares del federalismo argentino, y que la misma no parecía derrumbarse ante los embates de un abstracto «Estado central». Reconocer la centralidad de la calidad provincial en el federalismo argentino no solo permite advertir la consistencia de las provincias como espacios organizadores de la producción federal de la representación política, sino que además echa luz sobre las razones por las cuales, en las décadas siguientes, los numerosos proyectos relativos a la representación parlamentaria de los Territorios experimentaron el mismo fracaso, sin importar la fuerza política de la que provenían, ni el carácter de oficialismo u oposición de la misma. Más que un régimen consagrado en la letra de la Constitución pero en la práctica falsea-

105 Linares Quintana, 1937: 106. 
do a causa de más poderosas fuerzas centralizadoras, parece necesario entender que ese federalismo resultó eficaz para responder, por supuesto que no de modo armónico ni definitivo, al desafío de mantener un orden político mientras tenían lugar nada menos que las transformaciones más aceleradas y profundas que la sociedad argentina haya conocido, entre las cuales destacaban un acelerado crecimiento de la población y una dramática expansión del territorio soberano.

\section{BiBLIOGRAFÍA}

Alonso, Paula, Entre la revolución y las urnas. Los orígenes de la Unión Cívica Radical y la política argentina en los años '90, Buenos Aires, Sudamericana, 2000.

Alonso, Paula, Jardines secretos, legitimaciones públicas. El partido Autonomista Nacional y la política argentina de fines del siglo XIX, Buenos Aires, Edhasa, 2010 .

Alonso, Paula, "Dinámicas federales en las dos últimas décadas del siglo XIX", Paula Alonso y Beatriz Bragoni (eds.), El sistema federal argentino. Debates y coyunturas (1860-1910), Buenos Aires, Edhasa, 2015: 199-221.

Alonso, Paula y Bragoni, Beatriz (eds.), El sistema federal argentino. Debates y coyunturas (1860-1910), Buenos Aires, Edhasa, 2015.

Bertoni, Lilia Ana, Patriotas, cosmopolitas y nacionalistas. La construcción de la nacionalidad argentina a fines del siglo XIX, Buenos Aires, Fondo de Cultura Económica, 2001.

Bonaudo, Marta y Sonzogni, Élida, "Los grupos dominantes entre la legitimidad y el control", Marta Bonaudo (ed.), Liberalismo, Estado y orden burgués (18521880), Nueva Historia Argentina, Tomo IV, Buenos Aires, Sudamericana, 1999, 27-96.

Botana, Natalio, "El federalismo liberal en Argentina: 1852-1930", Marcello Carmagnani (ed.), Federalismos latinoamericanos: México/Brasil/Argentina, México, Fondo de Cultura Económica, 1993: 224-255.

Botana, Natalio, El orden conservador. La política argentina entre 1880 y 1916, Buenos Aires, Sudamericana, 1994.

Botana, Natalio, La tradición republicana. Alberdi, Sarmiento y las ideas políticas de su tiempo, Buenos Aires, Sudamericana, 1997.

Botana, Natalio, El orden conservador. La política argentina entre 1880 y 1916, Buenos Aires, Edhasa, 2012. 
Botana, Natalio y Gallo, Ezequiel, De la República posible a la República verdadera (1880-1910), Biblioteca del Pensamiento Argentino, Tomo III, Buenos Aires, Ariel, 1997.

Bragoni, Beatriz y Míguez, Eduardo, "De la periferia al centro: la formación de un sistema político nacional, 1852-1880", Beatriz Bragoni y Eduardo Míguez (eds.), Un nuevo orden político. Provincias y Estado nacional, 1852-1880, Buenos Aires, Biblos, 2010: 9-28.

Castro, Martín, El ocaso de la república oligárquica. Poder, política y reforma electoral, 1898-1912, Buenos Aires, Edhasa, 2012.

Cortés Conde, Roberto, El progreso argentino. 1880-1914, Buenos Aires, Sudamericana, 1979.

De Privitellio, Luciano, "Representación política, orden y progreso. La reforma electoral de 1902", Política y Gestión, 9 (Buenos Aires, 2006): 109-134.

De Privitellio, Luciano, "Las elecciones entre dos reformas: 1900-1955", Hilda Sabato, Marcela Ternavasio, Luciano De Privitellio y Ana Virginia Persello, Historia de las elecciones en la Argentina. 1805-2011, Buenos Aires, El Ateneo, 2011: 135-233.

Estrada, José Manuel, Curso de derecho constitucional, federal y administrativo. Conferencias dadas en la Universidad de Buenos Aires en los años 1877, 1878 y 1880, Buenos Aires, Compañía Sud-Americana de billetes de banco, 1895.

Favaro, Orietta y Arias Bucciarelli, Mario, "El lento y contradictorio proceso de inclusión de los habitantes de los territorios nacionales a la ciudadanía política: un clivaje de los años '30”, Entrepasados. Revista de Historia, 9 (Buenos Aires, 1995): 7-26.

Gallo, Ezequiel, "Política y sociedad en Argentina, 1870-1916", Leslie Bethell (ed.), Historia de América Latina. América del Sur, c. 1870-1930, Tomo X, Barcelona, Crítica, 1992: 41-66.

Gallo, Ezequiel, Alem. Federalismo y radicalismo, Buenos Aires, Edhasa, 2009.

Gallo, Ezequiel, "Economía, sociedad y política en la Argentina (1870-1930)", La República en ciernes. Surgimiento de la vida política y social pampeana, 18501930, Buenos Aires, Siglo XXI, 2013a: 19-90.

Gallo, Ezequiel, "Un quinquenio difícil: las presidencias de Carlos Pellegrini y Luis Sáenz Peña (1890-1895)", La República en ciernes. Surgimiento de la vida política y social pampeana, 1850-1930, Buenos Aires: Siglo XXI, 2013b: 91-122.

Gallucci, Lisandro, "La extensión del federalismo sobre el desierto argentino. Los debates parlamentarios en la sanción de la ley de Territorios Nacionales (1884)", Anuario de Estudios Americanos, 72 (2) (Sevilla, 2015): 693-722. https://doi. org/10.3989/aeamer.2015.2.11 
Gallucci, Lisandro, "El espejismo de la República posible. La cuestión de la ciudadanía política y la organización institucional de los Territorios Nacionales (1884)", Historia Crítica, 60 (Bogotá, 2016): 61-80. https://doi.org/10.7440/histcrit60.2016.04

Gibson, Edward y Falleti, Tulia, "La unidad a palos. Conflicto regional y los orígenes del federalismo argentino", PostData, 12 (Buenos Aires, 2007): 171-204.

González, Joaquín V., Manual de la Constitución Argentina. Escrita para servir de texto de instrucción cívica en los establecimientos de instrucción secundaria, Buenos Aires, Ángel Estrada y Ca. Editores, 1897.

Halperin Donghi, Tulio, "1880: un nuevo clima de ideas", El espejo de la historia. Problemas argentinos y perspectivas latinoamericanas, Buenos Aires, Sudamericana, 1998: 239-252.

Linares Quintana, Segundo, Derecho público de los territorios nacionales argentino y comparado, Buenos Aires, Talleres gráficos Porter hnos, 1937.

Otero, Hernán, Estadística y Nación. Una historia conceptual del pensamiento censal de la Argentina moderna, 1869-1914, Buenos Aires, Prometeo, 2006.

Pizarro, Manuel D., "Carta sobre la muerte de la federación argentina", Revista de Derecho, Historia y Letras, II, (Buenos Aires, 1898): 222-231.

Reyes, Francisco, "«Conmemorar la revolución y sus mártires». Sobre el lugar de un ritual político en la constitución de la identidad del radicalismo (1891-1897)", Estudios Sociales, 50, (Santa Fe, 2016): 41-76. https://doi.org/10.14409/es. v50i1.5947

Reynoso, Diego, "El reparto de la representación. Antecedentes y distorsiones de la asignación de diputados a las provincias", PostData, 17 (Buenos Aires, 2012): 153-192.

Rojkind, Inés, “«La revolución está vencida, pero el gobierno está muerto». Crisis política, discursos periodísticos y demostraciones callejeras en Buenos Aires, 1890", Anuario de Estudios Americanos, LXIX/2 (Sevilla, 2012): 507-532. https:// doi.org/10.3989/aeamer.2012.2.05

Ruffini, Martha, La pervivencia de la República posible en los territorios nacionales. Poder y ciudadanía en Río Negro, Bernal, Universidad Nacional de Quilmes, 2007.

Sabato, Hilda, "El ciudadano en armas: violencia política en Buenos Aires (18521890)", Entrepasados, 23 (Buenos AIres: 2003): 149-169.

Sabato, Hilda, “«Resistir la imposición»: revolución, ciudadanía y república en la Argentina de 1880", Revista de Indias, LXIX/246 (Madrid, 2009): 159-182. https://doi.org/10.3989/revindias.2009.016

Sabato, Hilda, Historia de la Argentina, 1852-1890, Buenos Aires, Siglo XXI, 2012.

Zimmermann, Eduardo, Los liberales reformistas. La cuestión social en la Argentina. 1890-1916, Buenos Aires, Sudamericana, 1995. 
Fecha de recepción: 25 de abril de 2018.

Fecha de envío de las modificaciones: 6 de septiembre de 2018.

Fecha de aceptación: 18 de febrero de 2019.

\section{Adjusting Representation to the Consequences of Progress. The Argentine Constitutional Reform of 1898 and the Dilemmas of Federalism}

This paper offers an analysis of the Argentine constitutional reform of 1898 , mostly overlooked by historiography on the period. In particular, it aims to explore the reasons why the reformative convention introduced certain changes into the federal representative system at the same time as it discarded others. Thus it seeks to contribute to a more complex image of Argentine politics between 1880 and 1916.

Key words: Political History; Argentina; Constitution; Federalism. 